\title{
EDITORIAL
}

\section{The June Issue of the CGJ}

DOI:http://dx.doi.org/10.5770/cgj.19.241

Our June issue presents a wide variety of research in numerous Canadian settings, including acute care, long-term care, and community dwelling older adults. Dr. Salina Juma et $a l .^{(1)}$ has examined the use of a clinical frailty scale to predict length of stay in acute care. Dr. Randall Sargent et al. ${ }^{(2)}$ has examined the use of a warfarin protocol in long-term care. The clinical implications of the new criteria for Alzheimer's disease are succinctly examined in an article by Drs. Pierre Molin and Kenneth Rockwood. ${ }^{(3)}$ The use of a core competency based program in residency education is explored by Dr. Lesley Charles et al. ${ }^{(4)}$ The use of art appreciation to help alleviate behavioural issues in community dwelling older adults is examined by Dr. Afeez Hazzan et al. ${ }^{(5)}$

Enjoy!

Dr. Kenneth Madden Editor-in-Chief Canadian Geriatrics Journal

\section{References}

1. Juma S, Taabazuing MM, Montero-Odasso M. Clinical frailty scale in an acute medicine unit: a simple tool that predicts length of stay. CGJ. 2016;19(2):34-39.

2. Sargent R, Brocklebank C, Tam-Tham H, et al. Advantages of a warfarin protocol for long-term care pharmacists: a retrospective cohort study. CGJ. 2016;19(2):40-49.

3. Pierre Molin, Kenneth Rockwood. The new criteria for Alzheimer's disease-implications for geriatricians. CGJ. 2016;19(2):66-73.

4. Charles L, Triscott J, Dobbs B, et al. Effectiveness of a core-competency-based program on residents' learning and experience. CGJ. 2016;19(2):50-57.

5. Hazzan AA, Humphrey J, Kilgour-Walsh L, et al. Impact of the 'Artful Moments' intervention on persons with dementia and their care partners: a pilot study. CGJ. 2016;19(2):58-65. 